\title{
CLINICO-MYCOLOGICAL STUDY OF OTOMYCOSIS
}

\begin{tabular}{|l|l|l|l}
\hline ENT &
\end{tabular}

Dr. Saima Senior Resident, ENT Department of ENT- Maharishi Markandeshwar Institute of Tabassum Medical Sciences and Research, Mullana,(Distt-Ambala),Haryana, India

\begin{tabular}{ll}
\hline $\begin{array}{l}\text { Dr. Chandpreet } \\
\text { Kour }\end{array}$ & $\begin{array}{l}\text { Junior Resident, ENT Department of ENT- Maharishi Markandeshwar Institute of } \\
\text { Medical Sciences and Research, Mullana,(Distt-Ambala),Haryana, India }\end{array}$ \\
\hline
\end{tabular}

Dr. Sajid Iqbal*

Assistant Professor Surgery, Department of Surgery- Maharishi Markandeshwar Institute of Medical Sciences and Research, Mullana, (Distt-Ambala), Haryana, India.

*Corresponding Author

\section{ABSTRACT}

Otomycosis Is a common condition encountered in a general otolaryngology clinic setting so, We conducted a study with an aim to determine the frequency, common presenting symptoms, predisposing factors and spectra of fungi. Where we found that Patient with Otomycosis presents with nonspecific symptoms like pruritis, discomfort and pain in the ear, aural fullness, tinnitus, hearing impairment, and sometimes discharge, and also recurrence was seen in some cases which is very frustrating for both the patient and doctor as it frequently requires long-term treatment and followup. Mainstay of treatment involves removal of debris, thorough toileting of the external ear and the use of antimycotic agents.

Summary: Otomycosis is a very frustrating clinical entity for both the otolaryngologist as well as for patient. So educating people about the predisposing factors, risks, cause and care is an important concern to be addressed.

\section{KEYWORDS}

Otomycosis, Fungal, Mycological

\section{INTRODUCTION \\ Otomycosis Is a common condition encountered in a general otolaryngology clinic setting. It is an acute, subacute or chronic fungal infection of the external auditory meatus seen commonly in the tropical and subtropical regions of the world because fungi can grow better in these areas as it needs moisture and warmth to grow ${ }^{(1)}$. Sometimes bacteria can combine with the fungi and make the infection more complicated. Predisposing factors such as a failure in the ear's defense mechanisms (changes in the coating epithelium, changes in $\mathrm{pH}$, quantitative and qualitative changes in ear wax), bacterial infection, instillation of oil, dermatitis, unhygienic habits, hearing aid or a hearing prosthesis, habitual instrumentation, , swimming, broad spectrum antibiotic agents, steroids and cytostatic medication, neoplasia and immune disorders, all of which can render the host susceptible to the development of Otomycosis..$^{(2,3,4)}$}

Otomycosis presents with nonspecific symptoms like pruritis, discomfort and pain in the ear, aural fullness, tinnitus, hearing impairment, and sometimes discharge, and also recurrence is common which is very frustrating for both the patient and doctor as it frequently requires long-term treatment and follow-up. ${ }^{(5)}$

Sometimes, Otomycosis may be Refractory to treatment which challenges the clinician to determine whether it is an isolated entity or related to any other systemic disorder or the result of an underlying immunodeficiency disorder. Accurate diagnosis of otomycosis requires a high index of suspicion. The diagnosis is clinical and accompanied by microbiological confirmation.

Mainstay of treatment involves removal of debris, thorough toileting of the external ear and the use of antimycotic agents such as clotrimazole. $^{(6,7)}$

There are more than 50 different species of fungi that may be responsible for this infection. Common fungi include Aspergillus and Candida. ${ }^{(8)}$

We conducted this study with the aim to determine the frequency, common presenting symptoms, predisposing factors and spectra of fungi.

\section{METHODS MATERIALS:}

The study entitled "clinico-mycological study of otomycosis " is a prospective study which was carried out in ENT department of MMIMSR for a period of 1 year between MAY 2017 to April 2018. The sample size consist of 100 patients of both sexes and all age groups.
Inclusion Criteria: Patient with a clinical diagnosis of otomycosis (NEW CASES)

Exclusion Criteria: The patients who were already on treatment for otomycosis were excluded from the study.

Collection of Samples: Two samples were collected from the patients external auditory canal with the help of a sterile cotton Swab in all suspected cases. One swab was subjected to microscopic examination with $10 \% \mathrm{KOH}$ and the other swab was inoculated over Sabouraud's dextrose agar media for culture. Identification of fungi was done by standard microbiological procedures.

All the suspected cases of otomycosis were treated with aural toileting followed by dry mopping and microscopic suction clearance whenever required and the patients were put on topical antifungal ear drops for 3 weeks. The patients were reviewed at the end of $3 \mathrm{rd}$ week to note the regression of clinical features.

\section{RESULTS:}

A total of 100 specimens were collected from patients suspected of otomycosis based on clinical features. Fungal isolates were found in 92 specimens. $42(45.6 \%)$ of otomycotic patients were females and 50 $(54.3 \%)$ were males.

The most common age group with highest incidence of otomycosis was found between the age of 31 to 40 years (Table-1).

Table 1: Age And Sex Distribution

\begin{tabular}{|l|l|l|l|l|}
\hline Age & Female & Male & Cases(N=) & Percentage \\
\hline $10-20$ & 7 & 2 & 9 & $9.78 \%$ \\
\hline $21-30$ & 10 & 12 & 22 & $23.9 \%$ \\
\hline $31-40$ & 14 & 24 & 38 & $41.3 \%$ \\
\hline $41-50$ & 6 & 8 & 14 & $15.2 \%$ \\
\hline $51-60$ & 3 & 3 & 6 & $6.5 \%$ \\
\hline$>60$ & 2 & 1 & 3 & $3.2 \%$ \\
\hline Total & 42 & 50 & 92 & $100 \%$ \\
\hline
\end{tabular}

In our study the predominant complaints were itching( $86 \%)$ and otalgia $(78 \%)$,followed by ear block $(65 \%)$, ear discharge $(43.4 \%)$, hearing loss (25\%) and headache (21\%). More than 40 percent of the patients had all the symptoms (Table-2).

Table 2: Frequent Symptoms In Patients

\begin{tabular}{|l|l|}
\hline ITCHING & 80 \\
\hline OTALGIA & 72 \\
\hline
\end{tabular}




\begin{tabular}{|l|l|}
\hline EAR BLOCKAGE & 40 \\
\hline EAR DISCHARGE & 60 \\
\hline HEARING LOSS & 23 \\
\hline HEADACHE & 20 \\
\hline
\end{tabular}

Instrumentation of Ear for self cleaning or itching with unsterile ear buds, Car key, hair pin, or sticks was found to be the predominant predisposing factor of otomycosis. In our study $34.7 \%$ of the patients gave history of manipulation/trauma to the EAC. $22.8 \%$ of the patients gave history of using either antibiotic ear drops or use of nonsterile oil into ear. Also, $19.5 \%$ of our patients had associated systemic disease, $13.04 \%$ were swimmers and $9.7 \%$ had no predisposing factors (Table-3).

\section{Table 3: Predisposing Factors Of Otomycosis}

\begin{tabular}{|l|l|}
\hline TRAUMA/INSTRUMENTATION & 32 \\
\hline INSTILLATION OF ANTIBIOTIC/OIL & 21 \\
\hline IMMUNOCOMPROMISED/SYSTEMIC DISEASE & 18 \\
\hline SWIMMERS & 12 \\
\hline NONE & 09 \\
\hline
\end{tabular}

Out of 100 specimens collected, $92(92 \%)$ specimens yielded growth. All specimens yielded single organism. Aspergillus niger 41(44\%) was the predominant species isolated. Aspergillus flavus 26(28\%) was the second most common species isolated. Aspergillus fumigatus 16(17.3\%), Candida species $8(8.6 \%)$ and Penicillium species $1(1.08 \%)$ were the other species isolated (figure-1).

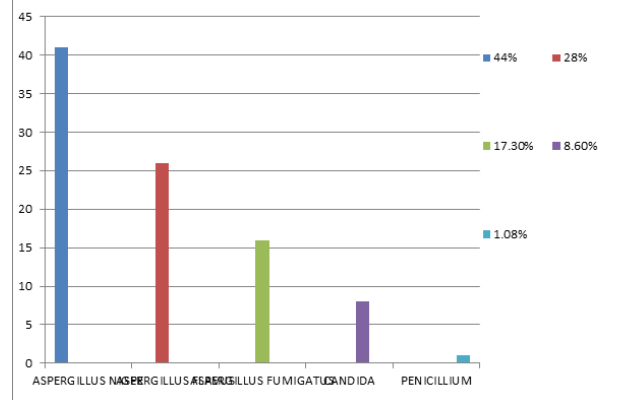

Figure 1: Fungal Isolates In Study Population

\section{DISCUSSION:}

An overview of literature reveals higher incidence of otomycosis in male patients than in females. ${ }^{(9)}$ Similar results were found in our study with an incidence of $54.34 \%$ in male and $45.65 \%$ in female.

The incidence of otomycosis in our study was high in the age group 21-40 years. This finding is similar to that of Aneja et $\mathrm{al}^{(10)} \&$ fasnula et al ${ }^{(11)}$.

common symptom of otomycosis found in our study was itching, pain and ear block followed by ear discharge, decreased hearing and headache. This is in agreement with other studies ${ }^{(12)}$.

Our study revealed that the most common predisposing factor for otomycosis was instrumentation/ trauma and hence inoculation of fungal debris in EAC with the damage of normal linning epithelium which is the natural defence to protect the ear from infections. Similar results were found by the study conducted by pontes et al ${ }^{(12) .}$

About the incidence of fungal spectra,we find that Aspergillus niger was the most commonly isolated organism found in EAC of patient suffering from otomycosis, which is in accordance with other studies ${ }^{(13)}$.

\section{CONCLUSION:}

Otomycosis is a very frustrating clinical entity for both the otolaryngologist as well as for patient because:

1. Clinical features are not specific so lab diagnosis is important to know the exact etiology

2. The long term treatment with appropriate antifungal therapy \&

3. The recurrence.

So educating people specially those living in rural tropical regions, immunocompromised patients, swimmers \& people with a habit of Ear instrumentation \& instilling oils etc about the predisposing factors, risks, cause and care is an important concern to be addressed.
REFERENCES:

1. Anaissie EJ, McGinnis MR, Pfaller MA. Clinical Mycology, Philadelphia, Elsevier Sciences 2003, p. 464.

2. Stern C, Lucente FE. Otomycosis. Ear Nose Throat J. 1988; 67:804-10.

3. Jackman A. Case report topical antibiotic induced otomycosis. Int J Pediatr Otorhinolaryngol. 2005;69:957-60

4. Sih T. Otite externa. Passages de Paris. 2005;2:166-71

5. Ho T, Vrabee JT, Yoo D. Coker NJ. Otomycosis: clinical features and treatment Implications. Otolaryngol Head Neck Surg. 2006;135(5):787-791

6. Raymundo Munguia, Sam J Daniel, McGill University, Montreal, Canada; Ototopical antifungals and otomycosis; A review. Int J of Pediatric Otorhinolaryngology (2008) 72, $453-459$

7. Jordan C Stern, Mahendra K Shah. Invitro effectiveness of 13 agents in Otomycosis and review of literature. Laryngoscope Nov 1988;98:1173-1177

8. Youssef YA, Abdou MH. Studies on fungus infection of the external ear Mycological and clinical observations. J Laryngol Otol. 1967;81(4):401-412

9. Than KM, Naing KS. And Min M. Otomycosis in Burma and its treatment. Am J Trop Med Hyg, 1980; 29(4): 620-623.

10. Aneja KR, Sharma C, Joshi R. Fungal infection of the ear: a common problem in the north eastern part ofHaryana. Int J Pediatr Otorhinolaryngol. 2010;74:604-7

11. Fasunla J, Ibekwe T, Onakoya P. Otomycosis in western Nigeria. Mycoses. 2008;51(1):67-70. doi: 10.1111/j.1439-0507.2007.01441.x.

12. Pontes ZB, Silva AD, Lima Ede O, Guerra Mde H, Oliveira NM, Carvalho Mde F, et al. Otomycosis: a retrospective study. Braz J Otorhinolaryngol. 2009;75(3):367-70.

13. Ghiacei S. Survey of Otomycosis in north-western area of Iran. Med J Mashhad Uni Med Sci $2001 ; 43: 85-7$ 